\title{
BONE AND SOFT TISSUE CHANGES AFTER ALVEOLAR RIDGE PRESERVATION USING PRF SOCKET PLUG TECHNIQUE VERSUS SOCKET PLUG TECHNIQUE: A SPLIT-MOUTH RANDOMISED CONTROLLED TRIAL
}

\author{
Sherif Ali * and Khaled Selim**
}

\begin{abstract}
Aim: The aim of this study was to compare platelet rich fibrin "PRF socket plug technique" versus the traditionally used "socket plug technique" to improve bone quality without affecting its volumetric stability. Research question: In mandibular premolars socket preservation, will "PRF socket plug" technique improve bone quality without affecting bone quantity, when compared to 'socket plug" technique? Materials and Methods: This was a split-mouth randomized controlled trial conducted on 9 patients. For each patient, bilateral socket preservation was performed. PRF socket plug technique (intervention) was performed for one side, while the other was performed using the traditional socket plug technique (control). After 6 months, bone and soft tissue changes were measured. Horizontal and vertical alveolar ridge loss and loss percentage were measured using cone-beam CT. Bone quality was measured by histomorphometric analysis of area percentages of mineralized trabecular bone of core biopsies. Keratinized mucosa changes were measured using Williams graduated periodontal probe. Results: Intervention group showed slightly higher horizontal bone loss, loss percentage, vertical bone loss, loss percentage $(1.36 \mathrm{~mm}, 16.98 \%$, $1.07 \mathrm{~mm}, 7.99 \%$ ) with no statistically significant difference when compared to the control group $(1.14 \mathrm{~mm}, 13.89 \%, 0.97 \mathrm{~mm}, 7.21 \%)$. Histomorphometric analysis showed higher new bone formation (34.11\%) in intervention group compared to the control group (30.78\%) with no statistically significant difference. Both groups showed keratinized mucosa gain $(1.28 \mathrm{~mm}$ intervention, $1 \mathrm{~mm}$ control) with no statistically significant difference. Conclusions: Socket plug technique is an effective technique for alveolar ridge preservation; PRF clot represents an easy, successful, and economical method to cover the graft in socket plug technique; PRF socket plug technique represents a promising alternative to the routinely used socket plug technique.
\end{abstract}

KEYWORDS: Socket preservation, Socket plug technique, Xenograft, Platelet concentrates, Platelet rich fibrin.

* Lecturer, Oral and Maxillofacial Surgery Department, Faculty of Dentistry, Cairo University, Cairo, Egypt.

** Lecturer, Oral Medicine and Periodontology Department, Faculty of Dentistry, Cairo University, Cairo, Egypt. 


\section{INTRODUCTION}

Dental implants are currently considered a routine treatment modality for replacing missing teeth. This enthusiastic intention has often clashed with the progressive tissue loss occurring after teeth extraction. Bone loss can reach up to $50 \%$ of the alveolar ridge width. The majority of these changes occur in the first 6 months. Moreover, this process is concentrated on the buccal bone results in the relocation of the ridge to a more lingual position ${ }^{1-6}$. Therefore, alveolar ridge preservation after tooth extraction has been introduced to maintain alveolar ridge, eliminating the need for different augmentation procedures before implant placement ${ }^{7-9}$.

Alveolar ridge preservation involves any procedure performed to eliminate or limit postextraction resorption, maintain ridge contour, promote bone formation and facilitate future implant placement ${ }^{10,11}$. The first attempts to preserve alveolar ridge was performed using submerged root concept ${ }^{12}$. Thereafter, different techniques have been introduced for alveolar ridge preservation. These techniques mainly differ in flap management, grafting material, and graft coverage ${ }^{11,13-16}$.

Traditionally alveolar ridge preservation was performed by socket filling (socket grafting) technique with or without GBR. In socket filling technique, extraction socket is grafted by different materials. The grafted socket is covered with barrier membrane in socket filling/GBR technique. Finally, the graft or/and membrane coverage is achieved by primary soft tissue closure. While in GBR, barrier membranes are used with ungrafted sockets. The principle of GBR involves the placement of barrier membrane to block in growth of soft tissue to the bone defect ${ }^{10,11,16-20}$.

The main drawback of previous techniques is the need of flap advancement to achieve primary soft tissue closure, leading to migration of mucogingival junction, reduction of available keratinized mucosa, increasing the risk of flap dehiscence and graft exposure, and increasing postoperative discomfort ${ }^{19-21}$. In a trial to overcome this drawback, socket seal technique was introduced. This technique utilizes a palatal soft tissue graft to cover the grafted socket. Although, socket seal technique eliminates the need of primary tissue closure, it is still associated with postoperative discomfort due to soft tissue donor site morbidity. Moreover, soft tissue graft harvesting needs skillful operator, and showed unpredictable results ${ }^{22-24}$.

Lately, "socket plug" technique has been introduced. "Socket plug" technique was primarily proposed by Sclar as "Bio-Col" technique. In the original technique Sclar suggested: (1) atraumatic extraction, (2) socket grafting with bovine bone, (3) collagen plug placement for graft coverage, (4) horizontal mattress suture to secure the plug, (5) cyanoacrylate over the collagen to harden and decrease collagen permeability, (6) oval pontic placement over surgical site ${ }^{25,26}$. Thereafter, various modifications have been introduced to improve and simplify the "Bio-Col' technique. The proposed modifications were concerned with handling and stabilization of collagen plug, suturing technique, and grafting materials. In 2014, Kotsakis et al ${ }^{24}$ introduced the term "socket plug" to describe different techniques using collagen dressing to cover grafted sockets. They recommended 4 distinct steps for this technique: (1) atraumatic flapless extraction, (2) socket grafting, (3) socket coverage with collagen dressing, (4) suturing ${ }^{24-30}$.

Although autogenous bone represented for years the gold standard in bone grafting procedures (for its osteogenic, osteoinductive and osteoconductive properties), its availability is countered by the morbidity associated with graft harvesting. Bone substitutes have been used as alternatives or supplements to autogenous bone. Those materials represent an attractive alternative for autogenous bone especially in implant grafting procedures. In such procedures, it should always be a priority 
to reduce patient morbidity to a minimum. It may be considered an aggressive method to harvest autogenous bone for small defects as extraction socket. Furthermore, bone substitutes showed higher volumetric stability compared to autogenous bone ${ }^{5,31-34}$.

Hard and soft tissue healing has been dramatically improved by the modulation of growth factors. The application of growth factors in bone tissue regeneration is mainly focused on the osteoinductive factors (as PDGF and BMPs) aiming to accelerate bone formation ${ }^{35,36}$. Platelet concentrates are considered as an alternative source of growth factors for its availability and cost. They are autologous fibrin adhesives with a high platelet concentration and high quantities of key growth factors (such as PDGF, TGFß1, TGFß2, VEGF, IGF, EGF, FGF) ${ }^{37,38}$.

PRP and PRGF represents the first generation of platelets concentrates. All available PRP and PRGF techniques have some points in common: (1) blood collection from the patient with anticoagulant to avoid platelet activation and degranulation, (2) differential centrifugation, (3) platelet concentrate application, together with activator ${ }^{37,39,40}$. In 2001, PRF was developed by Choukroun et al ${ }^{41}$. PRF is neither fibrin glue nor classical platelet concentrate. PRF protocol needs no anticoagulant or activator. The blood is collected into glass tubes without anticoagulant, and immediately centrifuged ${ }^{37,40,42}$. Unlike other platelets concentrates, platelets activation during the centrifugation process leads to substantial embedding of growth factors within the formed fibrin matrix. Being simply prepared and of low cost compared to other growth factors, PRF remains on the top of the list when choosing a reliable and a convenient regenerative material ${ }^{43-45}$.

Ever though socket plug technique showed promising results, almost all previously published clinical trials are case reports and series. In this randomised controlled trial, we introduce the use of "PRF socket plug technique" and compared it to the traditionally used "socket plug technique" in a trial to improve bone quality without affecting its volumetric stability.

\section{PICO question}

In mandibular premolars socket preservation, will "PRF socket plug" technique improve bone quality without affecting bone quantity, when compared to "socket plug" technique?

\section{MATERIALS AND METHODS}

\section{A) Trial design}

This was a split-mouth randomised controlled clinical trial. For each patient bilateral socket preservation was performed. Socket plug technique was performed for one side (control side), while the other (intervention side) was performed using the PRF socket plug technique (Fig. 1).

\section{B) Participants}

This study was conducted on 9 patients (6 female, 3 male aged between 29 and 47 years) selected from the out-patient clinic, Department of Oral and Maxillofacial Surgery, Faculty of Oral and Dental Medicine, Cairo University from December 2016 to January 2018.

Patients were selected according to the following criteria: Adult patients with bilateral non restorable mandibular premolars indicated for extraction; normal blood counts; free from any systemic disease or local condition that may affect normal bone and soft tissue healing, and predictable outcome, or contraindicate implant placement; nonsmokers; sockets maintaining a five wall defect after extraction. Any patients with acute infection or periapical lesion related to the area to be grafted were excluded.

\section{C) Interventions}

Patients were assessed clinically to assure their correspondence with eligibility criteria. Complete 
blood count was requested to assure normal blood counts. Preoperative panoramic radiograph was performed for each patient to assess root morphology, and exclude the presence of any periapical lesions. Every patient has undergone scaling and root planning to assure a more hygienic environment before the extraction procedure, and minimizing the risk of infection. Patient specific radiographic stent was fabricated for each patient using $2 \mathrm{~mm}$ thick clear vacuum sheets. Stents were fabricated to cover the lower dental arch (including non-restorable teeth). Gutta percha radiographic markers were fixed at the coronal, buccal, and lingual aspects of the stent at the treatment sites to act as reference points for measurements standardization.

Surgical procedures were performed under local anesthesia using Articane with Epinephrine 1:100,000 (Artinibsa, Inibsa, Barcelona, Spain). Patients were instructed to rinse their mouth with Chlorohexidine Gluconate $0.1 \% *$ mouth wash (Antiseptol, Kahira Pharma Co, Cairo, Egypt). Flapless atraumatic extraction was performed using periotomes. Periotomes were used to cut periodontal fibers at the cervical area. The tip of the periotome was inserted at the root mesial and distal line angles parallel to the root, with the blade located at the tip of the crestal bone. The periotome was then inserted into the periodontal ligament space and moved around the whole root surface area. The periotome was then directed apically towards the root apex and the process continued up to two thirds of the root. The final step of the extraction was performed using conventional extraction forceps. Forceps was used to extract the tooth (remaining root) with minimal force applied to forceps handles to avoid fracture or crushing of the tooth. Finally, extraction socket was examined to ensure the presence of five walls defect, and bone curette was used to debride the socket and remove any soft tissue remnants (Fig. 2).

Socket preservation was performed with traditional "socket plug" technique for the control side, and with "PRF socket plug" technique for the other. For the control side, xenograft particles (0.25- 1 particles, Tutobone, RTI Biologics ${ }^{T M}$ Tutogen medical GmbH, Germany) were hydrated with saline and used to fill the socket. Collagen plug (Collaplug, Zimmer Dental Inc, Carslsbad CA, USA) was trimmed and adapted over the socket to cover the graft. Finally, the plug was stabilized with figure of eight suture using 3/0 black silk. Minimal tension was applied to the suture to preserve soft tissue architecture (Fig. 3).

For intervention side, $10 \mathrm{ml}$ venous blood was drawn from the patient using plastic syringe to prepare PRF. Blood was immediately collected in $10 \mathrm{ml}$ dry glass test tube. The tube was immediately centrifuged at $3000 \mathrm{rpm}$ (about $400 \mathrm{x} \mathrm{g}$ ) for 12 minute. After centrifugation, PRF (middle layer) was formed with acellular platelet poor plasma (top layer), and red blood cells (base layer) ${ }^{43}$. PRF clot was removed from the tube and the attached red blood cells layer was scraped off and discarded. Scissors was used to cut PRF clot to 2 pieces. One clot was pressed using PRF piston and cylinder to form PRF plug. While the other was cut into small pieces and mixed with grafting material. The socket was filled with the hydrated graft particles mixed with PRF. Finally, PRF plug was adapted over the socket to cover the graft, and stabilized with figure of eight suture 3/0 black silk (Fig. 4).

Postoperative instructions and medications were: extraoral ice packs for first postoperative six hours, non-steroidal anti-inflammatory analgesic (Diclofenac potassium 50mg, Catafast tablets, Novartis Pharma AG, Cairo, Egypt) for three days, antibiotic (Clindamycin $300 \mathrm{mg}$, Clindam capsules, Sigma pharmaceutical industries, Egypt) for five days, Regular oral hygiene measures were resumed after 24 hours. Patients were recalled 1 week postoperatively for suture removal and clinical evaluation. The clinical evaluation included assessment of postoperative complications and soft 
tissue healing. Next visits were scheduled at 1, 3 and 6 months postoperatively.

Postoperative CBCT radiographs were performed for every patient 1 week $\left(\mathrm{T}_{0}\right)$ and 6 months $\left(\mathrm{T}_{6}\right)$ postoperatively. The radiographs were made with the same machine and same exposure parameters, with the radiographic stent seated in place to standardize radiographic measurements. Image reconstruction was performed using special software (Ondemand 3D version 1.0.9, Cybermed, Korea).

Second stage surgery was performed 6 months after socket grafting. It involved biopsy harvesting and implant placement. Bone core biopsy was collected from each socket before implant placement using a $3 \mathrm{~mm}$ diameter trephine bur. Biopsy samples were fixed immediately in $10 \%$ buffered formalin. Decalcification of the specimens were achieved by suspension in EDTA $10 \%$ solution for one week with regular renewal of the solution daily. After decalcification the specimens were dehydration using ascending alcohol, followed by clearing in xylol, then they embedded in paraffin wax to form a block. The paraffin block was sectioned longitudinally using a microtome into thin paraffin sections, each of approximately 5 microns thick. Sections were stained using Masson Trichrome stain for histomorphometric analysis.

\section{D) Outcomes}

The primary end point of radiographic analysis was the change in alveolar bone width. Additional analysis was done for the alveolar bone height change. Radiographic measures were performed on the cross-sectional cuts of CBCT. To assess horizontal alveolar bone loss (width loss), the alveolar bone width was measured at below the alveolar crest at the base line $\left(\mathrm{W}_{0}\right)$ and after 6 month $\left(\mathrm{W}_{6}\right)$. Then, horizontal bone loss and loss percentage were calculated as follow: Horizontal bone loss $\left(\mathrm{L}_{\mathrm{w}}\right)$, the difference between bone width at base line and after 6 months $\left(\mathrm{W}_{0}-\mathrm{W}_{6}\right)$; Horizontal bone loss percentage $\left(\mathrm{PL}_{\mathrm{W}}\right)$, percentage of the bone loss $\left(\mathrm{L}_{\mathrm{W}}\right)$ to the base line width $\left(\mathrm{W}_{0}\right)$. To assess vertical alveolar bone loss (height loss), the alveolar bone height was measured from the deepest point of the socket base to the bone crest at the base line $\left(\mathrm{H}_{0}\right)$ and after 6 month $\left(\mathrm{H}_{6}\right)$. Then, vertical bone loss and loss percentage were calculated as follow: Vertical bone loss $\left(\mathrm{L}_{\mathrm{H}}\right)$, the difference between bone width at base line and after 6 months $\left(\mathrm{L}_{0}-\mathrm{L}_{6}\right)$; Vertical bone loss percentage $\left(\mathrm{PL}_{\mathrm{H}}\right)$, percentage of the bone loss $\left(\mathrm{L}_{\mathrm{W}}\right)$ to the base line width $\left(\mathrm{W}_{0}\right)$. The radiographic stent was used to replicate the same measuring points at different time points for each patient (Fig. 5).

The end point of histomorphometric analysis was percentage of newly formed bone. Histomorphometric analysis was performed using image analyzer computer system (Leica QWin 500, Leica Microsystems Inc. Buffalo Grove, IL 60089 United States). Additional analysis was performed for remnants of bone substitute. Areas of newly formed bone, remnants of bone substitute were measured as a percentage of the total area for each core biopsy harvested from grafted sockets. In Masson Trichrome stained samples, new bone was identified in blue, and bone substitute remnants in red (Fig. 6).

Keratinized mucosa was measured at the mid buccal aspect of the tooth using a Williams graduated periodontal probe. Base line keratinized mucosa was performed between the mucoginigval line and the gingival margin, while after 6 months the measurement was done between mucogingival junction and the most crestal part of the edentulous ridge. To determine the keratinized mucosa gain for each socket, 6 months measure was subtracted from the base line measure.

\section{E. Sample size}

Based on previous study by Festa et al ${ }^{46}$, the difference in horizontal alveolar bone loss between 
the 2 groups was $1.9 \mathrm{~mm} \pm 1.2$. Using power of $80 \%$ and 5\% significance level, we needed to study 7 sockets in each group. The number was increased to a total sample size of $\mathbf{9}$ in each group to compensate for $20 \%$ losses during follow up. Sample size calculation was achieved using PS: Power and Sample Size Calculation software Version 3.1.2 (Vanderbilt University, Nashville, Tennessee, USA).

\section{F) Randomisation}

For each patient, one side was randomly allocated to control group, and the other side to intervention group. Randomisation was performed using 9 sheets of standard size paper. "Control/right side" was written on 5 sheets, "Control/left side" was written on the other 4 sheets. Paper sheets were then placed in 9 opaque sealed envelopes till start of surgical procedures. For each patient, an envelope was opened after patient eligibility assessment, preoperative preparation, and before starting the surgical procedure.

\section{G) Blinding}

This was a double blinded study. Outcome assessor and statistical data analyst were kept blinded. Whereas, participants and interventionists involved in the surgical procedures were aware with group allocation due to the nature of the procedure.

\section{H) Statistical analysis}

Statistical analysis was performed using SPSS (Statistical package for the social sciencesIBM® ${ }^{\circledR}$ SPSS ${ }^{\circledR}$ Statistics Version 20 for Windows, IBM Corp., Armonk, NY, USA). The data were represented as mean \pm standard deviation. Data were explored for normality using KolmogorovSmirnov and Shapiro-Wilk tests. For parametric data; Paired t-test was used to compare variables between the two groups. For non-parametric data; Wilcoxon signed-rank test was used. The results were considered statistically significant if the $p$ value was less than 0.05 .

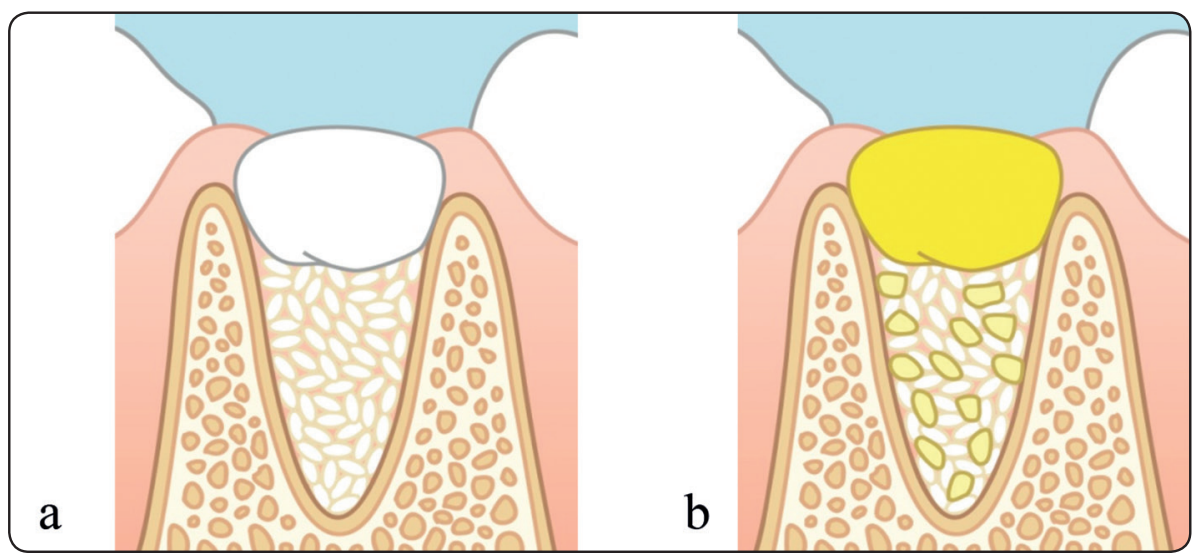

Fig. (1) a. Socket plug technique: the socket is filled with bone substitute particles and covered by socket plug. b. PRF socket plug technique: the socket is filled with bone substitute/PRF mixture and covered by PRF clot.

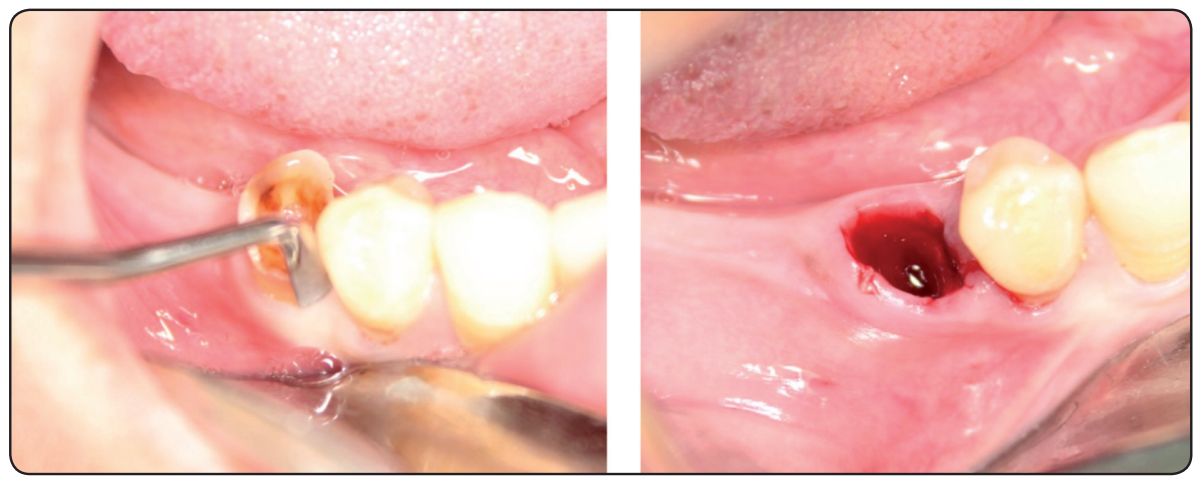

Fig. (2) a. Periotome inserted at the root line angle parallel to the root. b. Extraction socket after flapless atraumatic extraction. 


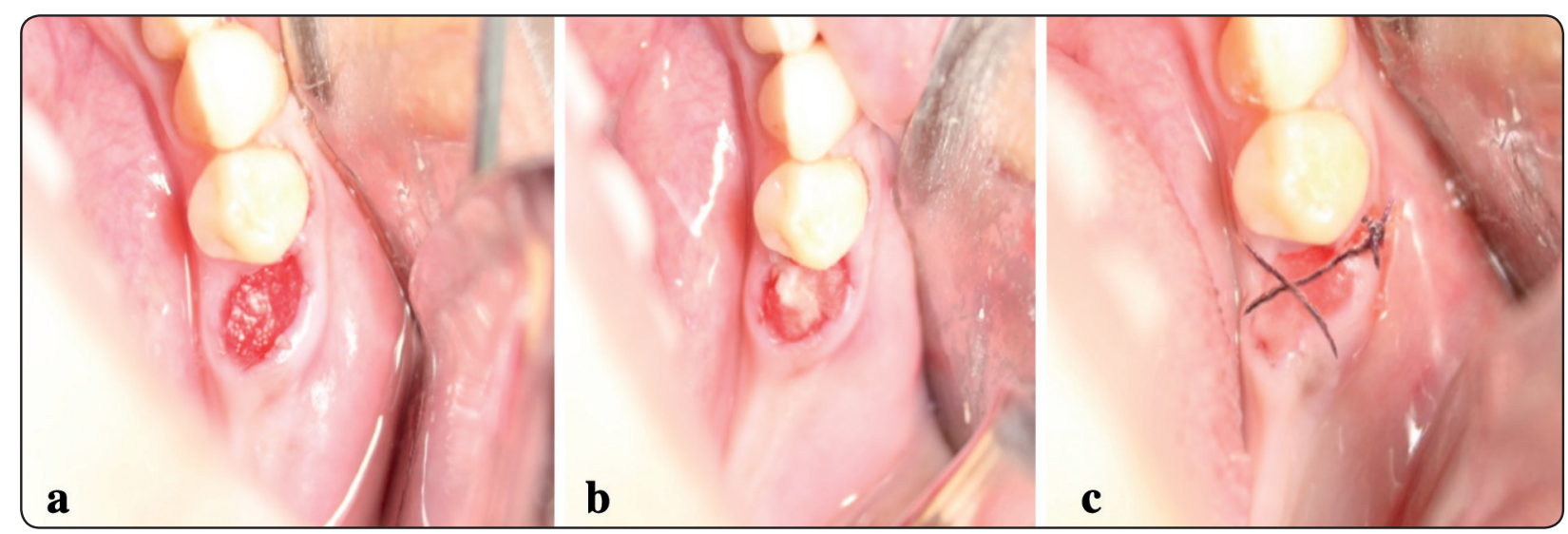

Fig. (3) Socket plug technique. a. Socket filled by xenograft particles. b. Collagen plug covering bone graft. c. Plug stabilized with figure of eight suture.
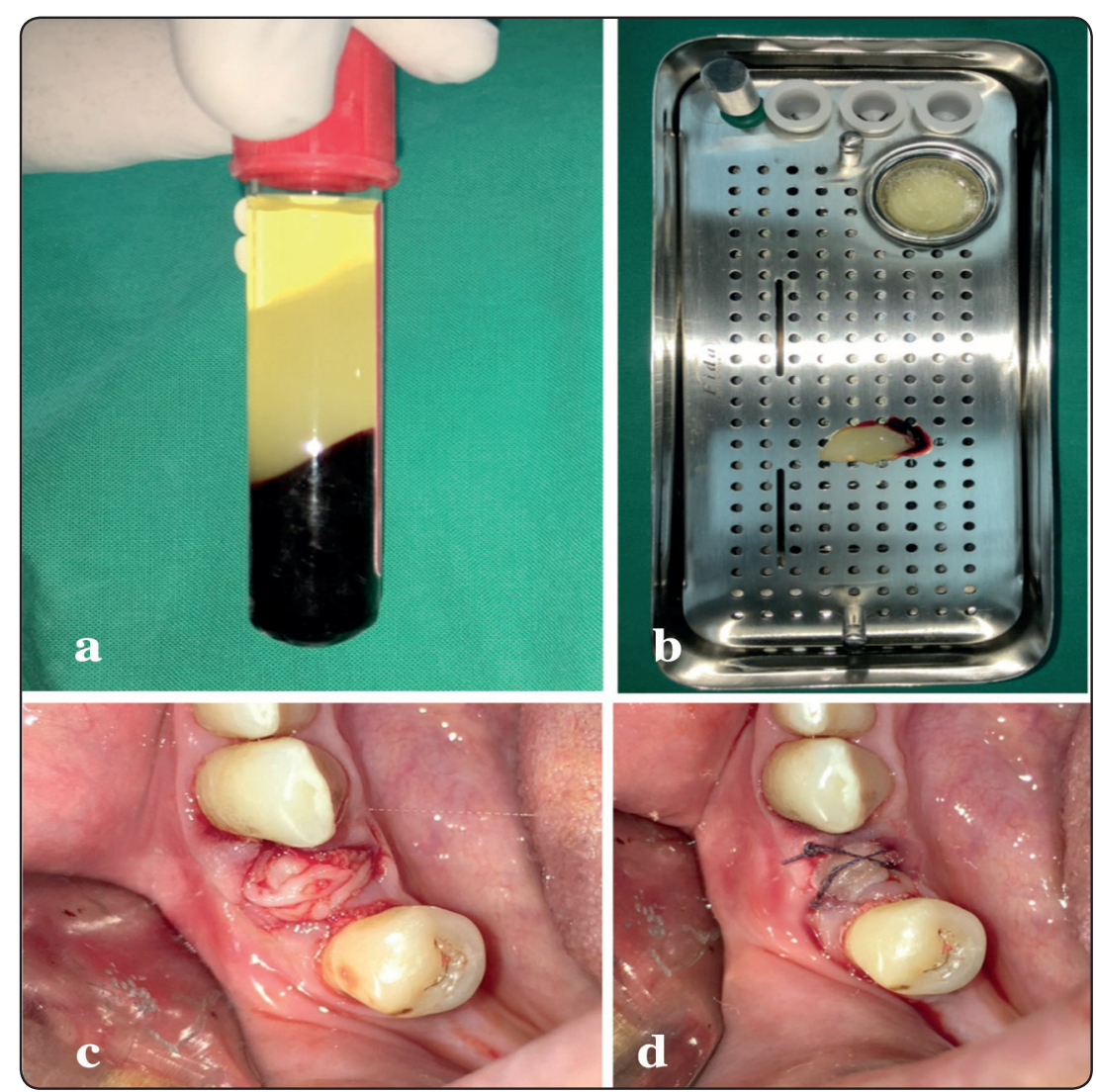

Fig. (4) PRF socket plug technique. a. PRF (middle layer) between acellular plate poor plasma (top layer), and red blood cells (base layer). b. PRF box kit with the piston and cylinders c. PRF clot covering grafted socket. c. PRF clot stabilized with figure of eight suture. 


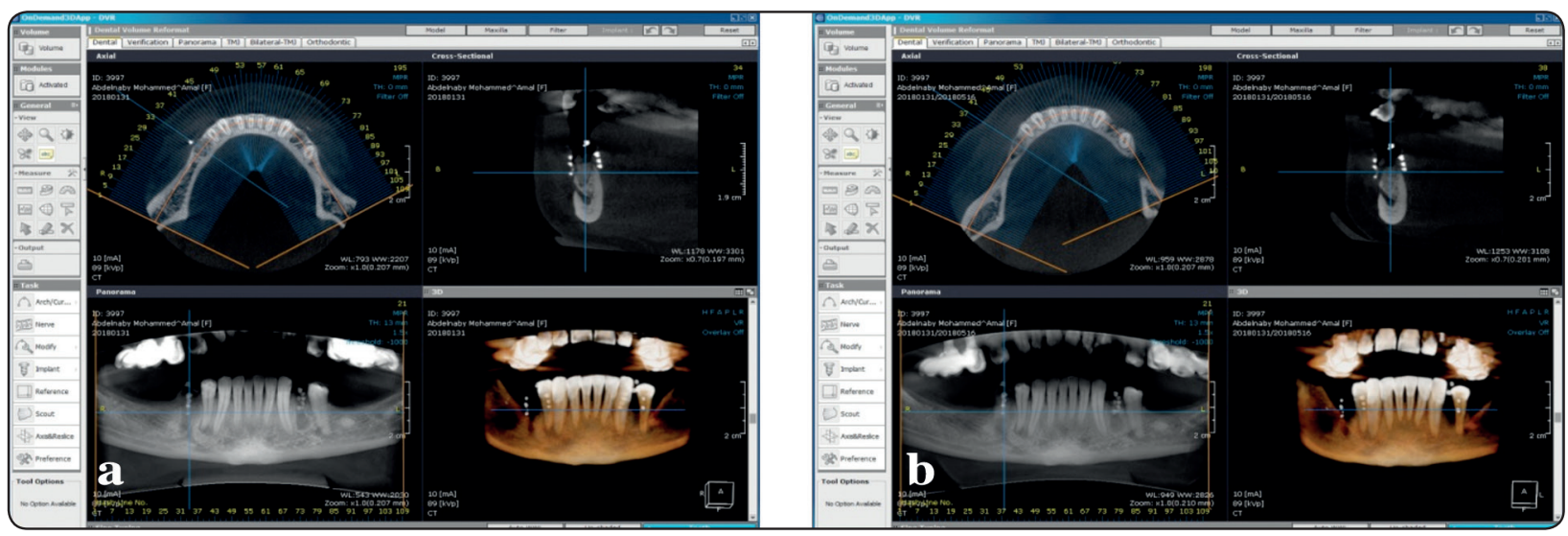

Fig. (5) Postoperative CBCT. a. 1 week postoperative CBCT. b. 6 months postoperative CBCT.

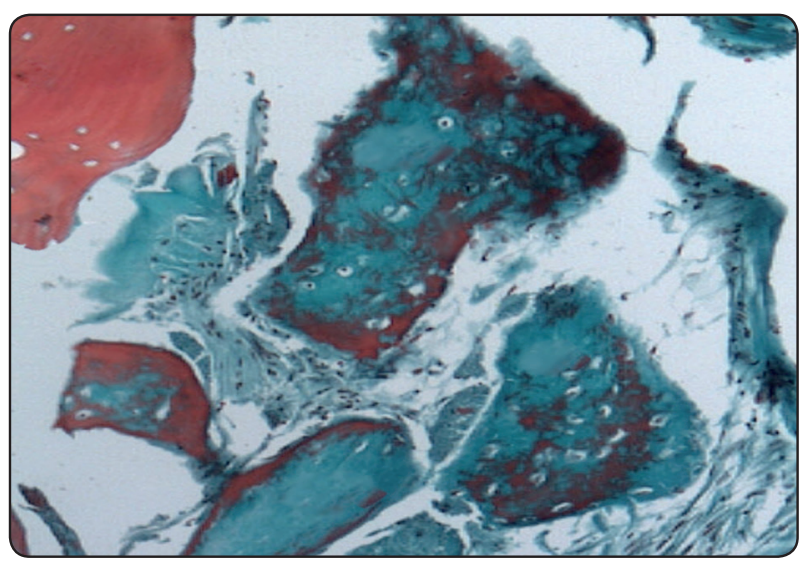

\section{RESULTS}

Intervention group showed slightly higher horizontal bone loss, horizontal bone loss percentage, vertical bone loss, and vertical bone loss percentage $(1.36 \pm 0.24 \mathrm{~mm}, 16.98 \pm 2.39 \%$, $1.07 \pm 0.31 \mathrm{~mm}, 7.99 \pm 2.1 \%)$ when compared to the control group $(1.14 \pm 0.35 \mathrm{~mm}, 13.89 \pm 3.48$ $\%, 0.97 \pm 0.18 \mathrm{~mm}, 7.21 \pm 1.25 \%$ ). There was no statistically significance difference between the 2 groups for all measures ( $\mathrm{P}$ value $>0.05$ ) (Fig. 7 , Table 1).

\section{Histomorphometric Analysis}

Intervention group showed higher new bone formation $(34.11 \pm 6.07 \%)$ compared to the control
Figure (6) Masson Trichrome stained section.

group $(30.78 \pm 5.93 \%)$, while control group showed higher bone substitute remnants $(31.89 \pm 6.39 \%)$ compared to intervention group $(29.33 \pm 5.1 \%)$. There was no statistically significance difference between the 2 groups for both measures ( $\mathrm{P}$ value $<$ 0.05) (Fig. 8).

\section{Clinical assessment}

Normal healing process was observed in both groups. Intervention group showed higher gain in the keratinized mucosa $(1.28 \pm 0.26 \mathrm{~mm})$ when compare to the control group $(1 \pm 0.5 \mathrm{~mm})$. There was no statistically significance difference between the 2 groups (P value $>0.05)$ (Fig. 9, Table 2) 
TABLE (1) Radiographic measures (Mean \pm standard deviation)

\begin{tabular}{|c|c|c|c|c|c|c|c|c|}
\hline & $\mathbf{W}_{\mathbf{0}}$ & $\mathbf{W}_{\mathbf{6}}$ & $\mathbf{L}_{\mathbf{w}}$ & $\mathbf{P L}_{\mathbf{w}}$ & $\mathbf{H}_{\mathbf{0}}$ & $\mathbf{H}_{\mathbf{6}}$ & $\mathbf{L}_{\mathbf{H}}$ & $\mathbf{P L}_{\mathbf{H}}$ \\
\hline Intervention & $7.97 \pm 0.67$ & $6.61 \pm 0.55$ & $1.36 \pm 0.24$ & $16.98 \pm 2.39$ & $13.29 \pm 1.09$ & $12.22 \pm 0.98$ & $1.07 \pm 0.31$ & $7.99 \pm 2.1$ \\
\hline Control & $8.14 \pm 0.5$ & $7 \pm 0.22$ & $1.14 \pm 0.35$ & $13.89 \pm 3.49$ & $13.42 \pm 1.04$ & $12.46 \pm 0.99$ & $0.97 \pm 0.18$ & $7.21 \pm 1.25$ \\
\hline
\end{tabular}

$\mathrm{W}_{0}$ Bone width at base line; $\mathrm{W}_{6}$ Bone width after 6 months; $\mathrm{L}_{\mathrm{w}}$ Horizontal bone loss; $\mathrm{PL}_{\mathrm{w}}$ Percentage of horizontal bone loss; $\mathrm{H}_{0}$ Bone height at base line; $\mathrm{H}_{6}$ Bone height after 6 months; $\mathrm{L}_{\mathrm{H}}$ Vertical bone loss; $\mathrm{PL}_{\mathrm{H}}$ Percentage of vertical bone loss

TABLE (2) Keratinized mucosa measures (Mean \pm standard deviation)

\begin{tabular}{|c|c|c|c|}
\hline & Baseline & 6 months & Gain \\
\hline Intervention & $2.44 \pm 0.58$ & $3.72 \pm 0.67$ & $1.28 \pm 0.26$ \\
\hline Control & $2.28 \pm 0.44$ & $3.28 \pm 0.57$ & $1 \pm 0.5$ \\
\hline
\end{tabular}

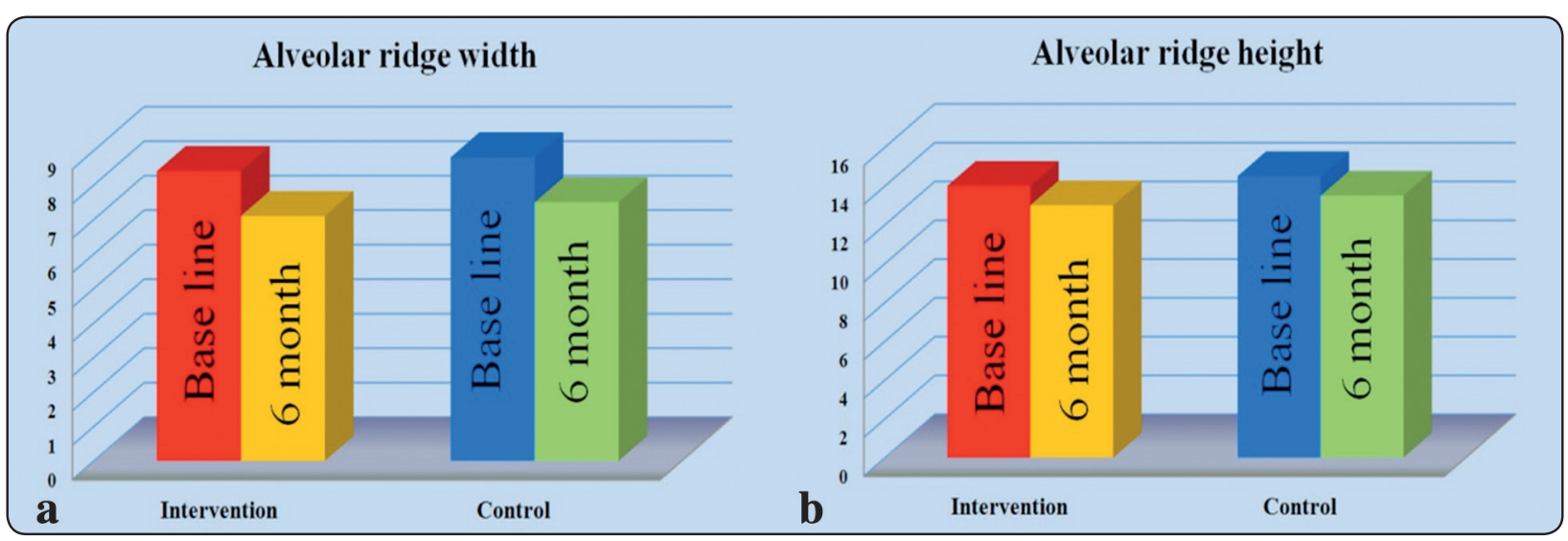

Fig. (7) Bar charts showing radiographic measures for both groups. a. Alveolar ridge width change. b. Alveolar ridge height change.

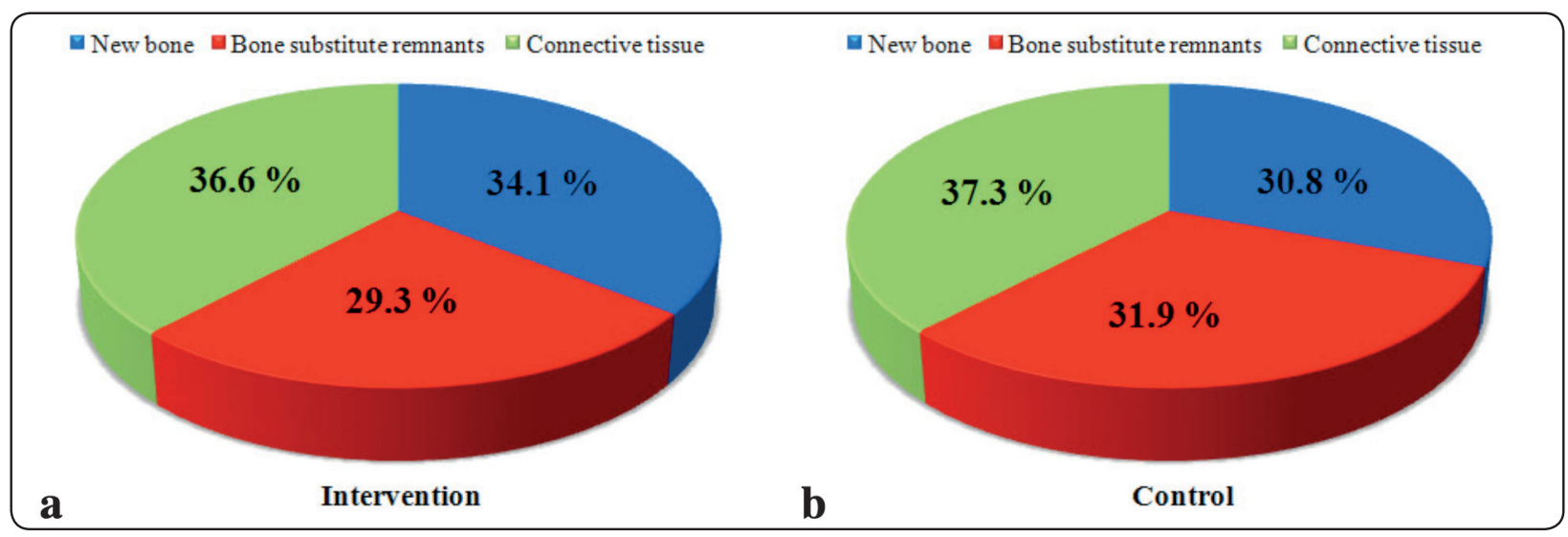

Fig. (8) Pie charts showing histomorphometric results of both groups. 


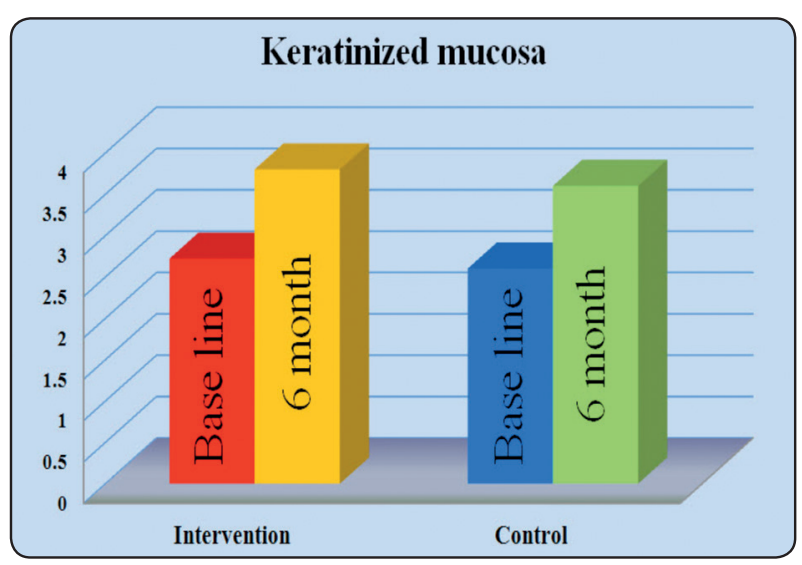

Fig. (9) Bar charts showing keratinized mucosa measures for both groups.

\section{DISCUSSION}

Alveolar ridge preservation has been introduced to maintain the existing soft and hard tissues, simplifying upcoming procedures, enhancing functional and esthetic results. Various techniques and protocols have been investigated, however the selection of the ideal technique still questionable ${ }^{10}$, ${ }^{15}$. This split-mouth randomised study was designed to introduce the use of "PRF socket plug" technique and test its efficiency for alveolar ridge preservation compared to the "socket plug" technique. The study report was prepared following the CONCORT 2010 guidelines for reporting randomised trials ${ }^{47}$.

The split-mouth design has been used in different clinical studies. The major advantage of this design is the isolation of treatment comparisons from the inter-subject variation; subsequently it obtains the same power with lower sample size when compared to parallel arm design ${ }^{48}$. In split-mouth studies, each patient should have more than one site indicated for treatment. To achieve this in our study, all patients were selected with bilateral non restorable mandibular premolars indicated for extraction and socket preservation.

In this study, the grafted sockets were covered by collagen plugs (control group) and PRF clots
(Intervention group). The collagen dressings were utilized to cover grafted sockets, prevent graft wash out, and induce clot formation. Furthermore, it enhances soft tissue coverage and encourages cell migration as collagen shows chemotactic properties for fibroblasts 16, 29, 49. In "PRF socket plug" technique, we induced the use of PRF clot instead the collage plug. PRF is not only an optimized blood clot to cover the graft, but also it is a matrix containing various elements enhancing migration of endothelial cells and fibroblasts, and tissue healing 43, 50. A recent systematic review by Miron et al highlighted this positive effect of PRF soft tissue healing ${ }^{51}$. Although, PRF group showed slightly higher keratinized mucosa gain, both groups showed higher results (1-1.28 mm gain) when compare to unassessted healing ( $0.9 \mathrm{~mm}$ loss to $0.4 \mathrm{~mm}$ gain $)^{2}$.

Recent histomorphometric meta-analysis by De Risi et al showed that xenograft ARP results in lower bone percentage after 6 months compared to other grafting materials ${ }^{15}$. To the contrary, xenograft slow biodegradation seems to maintain graft volume and prevent bone loss ${ }^{52}$. The optimal time for implant placement after socket grafting represents a true dilemma. With time, the alveolar ridge volume gradually decreases, while the bone quality gradually increases. Consequently, the implants should be placed as early as possible, but late enough to allow proper bone formation ${ }^{10,20}$. In this study, PRF fragments were mixed with xenograft particles in a trial to accelerate bone maturation without affecting its volumetric stability. Although, Histomorphometric analysis after 6 months showed higher new bone and lower xenograft remnants in the PRF group compared to control group, there was no statistically difference between both groups.

Both groups showed a high percentage of residual bone substitute. This result was correlated with various studies conducted on bovine bone showed retention of graft up to 3 years 16, 31, 53. Bovine bone seemed to act as semipermanent 
grafting material. Consequently, the final result of the grafted socket is formed of newly formed bone and the residual bone substitute ${ }^{54,55}$. It has been proven that such remaining material wouldn't hinder implants osteointegration. Berglundh and Lindhe 56 investigated in an experimental study bone healing around implants placed in bone defects grafted with bovine bone. Histological results showed the presence of mineralized bone separating graft particles from implants surfaces ${ }^{56}$.

Radiographic outcomes of our study showed comparable results in both groups. It showed that the addition of PRF to xenograft particles doesn't adversely affect its volumetric stability. Both groups showed vertical and horizontal bone loss. This result corresponds with various systematic reviews that demonstrated that different ARP techniques minimize, but don't totally eliminate post extraction alveolar bone resorption 10, 14, 32. However, both groups showed great results compared to unassisted socket healing. Tan et $\mathrm{al}^{2}$ conducted a meta-analysis to evaluate dimensional changes after 6 months of unassisted socket healing. Non grafted sockets showed horizontal dimensional reduction of 3.79 $\mathrm{mm}$ (ranging from 29-63\% of the original site width), vertical dimensional reduction of $1.24 \mathrm{~mm}$ (ranging from 11-22\% of the original site height) ${ }^{2}$.

Althought, PRF doesn't prove to have beneficial effect on xenograft maturation, "PRF socket plug" technique showed promising results compared to "socket plug" technique. It reduces the quantity of bone substitute used, eliminates the need of collagen plug; reducing the overall cost of the procedure without affecting volumetric stability. Despite the great advantages of both techniques, they have a major limitation. These techniques can be used only in five bony wall sockets. Any bony wall damages, dehiscence or fenestration indicates the need of barrier membrane to cover the graft at the defect site and prevent soft tissue in growth ${ }^{16,24,57}$.

\section{CONCLUSIONS}

Within the limitation of this study, we concluded that: Socket plug technique is an effective technique for alveolar ridge preservation; PRF clot represent an easy, successful, and economical method to cover the graft in socket plug technique; PRF socket plug technique represents a promising alternative to the routinely used socket plug technique.

\section{LIST OF ABBREVIATIONS}

PRF Platelet rich fibrin

GBR Guided bone regeneration

PDGF Platelet-derived growth factor

BMPs Bone morphogenetic proteins

TGFß Transforming growth factor beta

VEGF Vascular endothelial growth factor

IGF Insulin-like growth factor

EGF Epidermal growth factor

FGF Fibroblast growth factor

PRP Platelet-rich plasma

PRGF Plasma rich in growth factors

CBCT Cone beam computed tomography

\section{REFERENCES}

1. Grossberg DE: Interimplant papilla reconstruction: assessment of soft tissue changes and results of 12 consecutive cases. J Periodontol. 2001; 72:958-62.

2. Tan WL, Wong TLT, Wong MCM, Lang NP. A systematic review of postextractional alveolar hard and soft tissue dimensional changes in humans. Clin Oral Implants Res. 2012; 23(suppl 5):1-21.

3. Schropp L, Wenzel A, Kostopoulos L, Karring T. Bone healing and soft tissue contour changes following singletooth extraction: a clinical and radiographic 12-month prospective study. Int $\mathrm{J}$ Periodontics Restorative Dent. 2003; 23:313-23. 
4. Horowitz R, Holtzclaw D, Rosen PS. A review on alveolar ridge preservation following tooth extraction. J Evid Based Dent Pract. 2012 Sep; 12 (3 Suppl):149-60.

5. Van der Weijden, F., Dell'Acqua, F. \& Slot, D.E. Alveolar bone dimensional changes of post-extraction sockets in humans: a systematic review. Journal of Clinical Periodontology. 2009; 36:1048-58.

6. Elnayef B, Monje A, Lin GH, Gargallo-Albiol J, Chan HL, Wang HL, Hernández-Alfaro F. Alveolar ridge split on horizontal bone augmentation: a systematic review. Int J Oral Maxillofac Implants. 2015; 30(3):596-606.

7. Chiapasco M, Casentini P,Zaniboni M. Bone augmentation procedures in implant dentistry. Int J Oral Maxillofac Implants. 2009; 24(Suppl):237-59.

8. Becktor JP, Isaksson S, Sennerby L. Survival analysis of endosseous implants in grafted and nongrafted edentulous maxillae. Int J Oral Maxillofac Implants. 2004 Jan-Feb; 19(1):107-15.

9. Barone A, Ricci M, Tonelli P, Santini S, Covani U. Tissue changes of extraction sockets in humans: a comparison of spontaneous healing vs. ridge preservation with secondary soft tissue healing. Clin Oral Implants Res. 2013; 24:1231-7.

10. Horváth A, Mardas N, Mezzomo LA, Needleman IG, Donos N. Alveolar ridge preservation. A systematic review. Clin Oral Investig. 2013 Mar; 17(2):341-63.

11. Mardas N, Trullenque-Eriksson A, MacBeth N, Petrie A, Donos N. Does ridge preservation following tooth extraction improve implant treatment outcomes: a systematic review: Group 4: Therapeutic concepts \& methods. Clin Oral Implants Res. 2015 Sep; 26(Suppl 11):180-201.

12. Casey DM, Lauciello FR. A review of the submerged-root concept. J Prosthet Dent. 1980 Feb; 43(2):128-32.

13. Pagni G, Pellegrini G, Giannobile WV, Rasperini G. Postextraction Alveolar Ridge Preservation: Biological Basis and Treatments. Int J Dent. 2012; 2012:151030.

14. Vignoletti F, Matesanz P, Rodrigo D, Figuero E, Martin C, Sanz M. Surgical protocols for ridge preservation after tooth extraction. A systematic review. Clin Oral Implants Res. 2012; 23(Suppl 5):22-38.

15. De Risi V, Clementini M, Vittorini G, Mannocci A, De Sanctis M. Alveolar ridge preservation techniques: a systematic review and meta-analysis of histological and histomorphometrical data. Clin Oral Implants Res. 2015 Jan; 26(1):50-68.

16. Tomlin EM, Nelson SJ, Rossmann JA. Ridge preservation for implant therapy: a review of the literature. Open Dent J. 2014 May; 8:66-76.

17. Lee SW, Kim SG. Membranes for the Guided Bone Regeneration. Maxillofac Plast Reconstr Surg. 2014 Nov; 36(6):239-46.

18. Rakhmatia YD1, Ayukawa Y, Furuhashi A, Koyano K. Current barrier membranes: titanium mesh and other membranes for guided bone regeneration in dental applications. J Prosthodont Res. 2013 Jan; 57(1):3-14.

19. MacBeth N, Trullenque-Eriksson A, Donos N, Mardas N. Hard and soft tissue changes following alveolar ridge preservation: a systematic review. Clin Oral Implants Res. 2017 Aug; 28(8):982-1004.

20. Willenbacher M, Al-Nawas B, Berres M, Kämmerer PW, Schiegnitz E. The Effects of Alveolar Ridge Preservation: A Meta-Analysis. Clin Implant Dent Relat Res. 2016 Dec; 18(6):1248-68.

21. Engler-Hamm D, Cheung WS, Yen A, Stark PC, Griffin T. Ridge preservation using a composite bone graft and a bioabsorbable membrane with and without primary wound closure: A comparative clinical trial. J Periodontol Mar. 2011; 82(3): 377-87.

22. Thalmair T, Hinze M, Bolz W, Wachtel H. The Healing of Free Gingival Autografts for Socket-seal Surgery: a Case Report. Eur J Esthet Dent. 2010; 5(4):358-68.

23. Landsberg CJ. Implementing socket seal surgery as a socket preservation technique for pontic site development: surgical steps revisited--a report of two cases.J Periodontol. 2008 May;7 9(5):945-54.

24. Kotsakis G, Chrepa V, Marcou N, Prasad H, Hinrichs J. Flapless alveolar ridge preservation utilizing the "socketplug" technique: clinical technique and review of the literature. J Oral Implantol. 2014 Dec; 40(6):690-8.

25. Sclar AG. Preserving alveolar ridge anatomy following tooth removal in conjunction with immediate implant placement. The Bio-Col technique. Atlas Oral Maxillofac Surg Clin North Am. 1999 Sep; 7(2):39-59.

26. Fowler EB, Whicker R. Modified approach to the Bio-Col ridge preservation technique: a case report. J Contemp Dent Pract. 2004 Aug 15; 5(3):82-96. 
27. Sclar AG. Strategies for management of single-tooth extraction sites in aesthetic implant therapy. J Oral Maxillofac Surg. 2004 Sep; 62(9 Suppl 2):90-105.

28. Wang HL, Kiyonobu K, Neiva RF. Socket augmentation: rationale and technique. Implant Dent. 2004 Dec; 13(4):286-96.

29. Wang HL, Tsao YP. Mineralized bone allograft-plug socket augmentation: rationale and technique.Implant Dent. 2007 Mar; 16(1):33-41.

30. Mahesh L1, Venkataraman N, Shukla S, Prasad H, Kotsakis GA. Alveolar ridge preservation with the socketplug technique utilizing an alloplastic putty bone substitute or a particulate xenograft: a histological pilot study. J Oral Implantol. 2015 Apr; 41(2):178-83.

31. Jamjoom A, Cohen RE. Grafts for Ridge Preservation. J Funct Biomater. 2015 Aug 7; 6(3):833-48.

32. Ten Heggeler JM, Slot DE, Van der Weijden GA. Effect of socket preservation therapies following tooth extraction in non-molar regions in humans: a systematic review.Clin Oral Implants Res. 2011 Aug; 22(8):779-88.

33. Nkenke E, Stelzle F: Clinical outcomes of sinus floor augmentation for implant placement using autogenous bone or bone substitutes: a systematic review. Clin Oral Implants Res. 2009; 20 (Suppl 4):124-33.

34. Iezzi G, Degidi M, Piattelli A, Mangano C, Scarano A, Shibli JA, Perrotti V: Comparative histological results of different biomaterials used in sinus augmentation procedures: a human study at 6 months. Clin Oral Implants Res. 2012; 23(12):1369-76.

35. Sipe IP: Tissue Engineering and Reparative Medicine. Ann N Y Acad Sci. 2002; 961:1-9.

36. Bagheri SC, Bell RB, Khan HA: Tissue engineering. In: Current therapy in oral and maxillofacial surgery. Saunders, Elsevier. Pp 7-91, 2012.

37. Dohan DM, Choukroun J, Diss A, Dohan SL, Dohan AJ, Mouhyi J, Gogly B: Platelet-rich fibrin (PRF): a secondgeneration platelet concentrate. Part I: technological concepts and evolution. Oral Surg Oral Med Oral Pathol Oral Radiol Endod. 2006; 101(3):e37-44.

38. Froum SJ, Wallace SS, Tarnow DP, Cho SC: Effect of platelet-rich plasma on bone growth and osseointegration in human maxillary sinus grafts: three bilateral case reports. Int J Periodontics Restorative Dent. 2002; 22(1):45-53.
39. Kim TH, Kim SH, Sándor GK, Kim YD: Comparison of platelet-rich plasma (PRP), platelet-rich fibrin (PRF), and concentrated growth factor (CGF) in rabbit-skull defect healing. Arch Oral Biol. 2014; 59(5):550-8.

40. Dohan Ehrenfest DM, Rasmusson L, Albrektsson T: Classification of platelet concentrates: from pure plateletrich plasma (P-PRP) to leucocyte- and platelet-rich fibrin (L-PRF). Trends Biotechnol. 2009; 27(3):158-67.

41. Choukroun J, Adda F, Schoeffler C, Vervelle A: An opportunity in perio-implantology: The PRF. Implantodontie. 2001; 42:55-62.

42. Simonpieri A, Del Corso M, Sammartino G, Dohan Ehrenfest DM: The relevance of Choukroun's plateletrich fibrin and metronidazole during complex maxillary rehabilitations using bone allograft. Part I: a new grafting protocol. Implant Dent. 2009; 18(2):102-11.

43. Ali S, Bakry SA, Abd-Elhakam H. Platelet-Rich Fibrin in Maxillary Sinus Augmentation: A Systematic Review.J Oral Implantol. 2015 Dec; 41(6):746-53.

44. Dohan DM, Choukroun J, Diss A, Dohan SL, Dohan AJ, Mouhyi J, Gogly B: Platelet-rich fibrin (PRF): a secondgeneration platelet concentrate. Part II: platelet-related biologic features. Oral Surg. Oral Med. Oral Pathol. Oral Radiol. Endod. 2006; 101:e45-e50.

45. Dohan DM, Choukroun J, Diss A, Dohan SL, Dohan AJ, Mouhyi J, Gogly B: Platelet-rich fibrin (PRF): a second-generation platelet concentrate. Part III: leucocyte activation: a new feature for platelet concentrates. Oral Surg. Oral Med. Oral Pathol. Oral Radiol. Endod. 2006; 101:e51-e55.

46. Festa VM, Addabbo F, Laino L, Femiano F, Rullo R. Porcine-derived xenograft combined with a soft cortical membrane versus extraction alone for implant site development: a clinical study in humans. Clin Implant Dent Relat Res. 2013 Oct; 15(5):707-13.

47. Moher D, Hopewell S, Schulz KF, Montori V, Gøtzsche PC, Devereaux PJ, Elbourne D, Egger M, Altman DG. CONSORT 2010 explanation and elaboration: updated guidelines for reporting parallel group randomised trials. BMJ. 2010 Mar 23; 340:c869.

48. Shoukri MM, Colak D, Donner A. Likelihood inference on the relative risk in split-cluster designs. Clin Trials. 2011 Feb; 8(1):37-47. 
49. Postlethwaite AE, Seyer JM, Kang AH. Chemotactic attraction of human fibroblasts to type I, II, and III collagens and collagen-derived peptides. Proc Natl Acad Sci U S A. 1978 Feb; 75(2):871-5.

50. Choukroun J, Diss A, Simonpieri A, Girard MO, Schoeffler C, Dohan SL, Dohan AJ, Mouhyi J, Dohan DM. Plateletrich fibrin (PRF): a second-generation platelet concentrate. Part IV: clinical effects on tissue healing. Oral Surg Oral Med Oral Pathol Oral Radiol Endod. 2006 Mar; 101(3):e56-60.

51. Miron RJ, Fujioka-Kobayashi M, Bishara M, Zhang Y, Hernandez M, Choukroun J. Platelet-Rich Fibrin and Soft Tissue Wound Healing: A Systematic Review. Tissue Eng Part B Rev. 2017 Feb; 23(1):83-99.

52. Jensen T, Schou S, Stavropoulos A, Terheyden H, Holmstrup P: Maxillary sinus floor augmentation with Bio-Oss or Bio-Oss mixed with autogenous bone as graft: a systematic review. Clin Oral Implants Res. 2012; 23(3): 263-73.

53. Hallman M1, Lundgren S, Sennerby L. Histologic analysis of clinical biopsies taken 6 months and 3 years after maxillary sinus floor augmentation with $80 \%$ bovine hydroxyapatite and $20 \%$ autogenous bone mixed with fibrin glue. Clin Implant Dent Relat Res. 2001; 3(2):87-96.

54. Pettinicchio M, Traini T, Murmura G, Caputi S, Degidi M, Mangano C, Piattelli A: Histologic and histomorphometric results of three bone graft substitutes after sinus augmentation in humans. Clin Oral Investig. 2012; 16(1): 45-53.

55. Martinez A, Franco J, Saiz E, Guitian F: Maxillary sinus floor augmentation on humans: Packing simulations and 8 months histomorphometric comparative study of anorganic bone matrix and $\beta$ - tricalcium phosphate particles as grafting materials. Mater Sci Eng C Mater Biol Appl. 2010; 30(5): 763-9.

56. Berglundh T, Lindhe J. Healing around implants placed in bone defects treated with Bio-Oss. An experimental study in the dog. Clin Oral Implants Res. 1997 Apr; 8(2):117-24.

57. Misch C.E. (ed): Tooth extraction, socket grafting, and barrier membrane bone regeneration. In: Contemporary implant dentistery, 3rd edition. Mosby, Elsevier. Pp 870904, 2008. 